\title{
O declínio do welfare state e a emergência do estado prisional Tempos de um novo puritanismo?
}

\author{
Erni J. Seibel
}

Propõe-se, com este artigo, ${ }^{1}$ discorrer sobre o declínio do welfare state, apresentar as teses de Ladipo (2000) e Wacquant (2001), ${ }^{2}$ debater a tese da reedição do fenômeno puritano que orientou transformações sociais simultaneamente ao processo de transformação das relações capitalistas de produção nos primórdios do século XX que culminaram no desenvolvimento do modelo taylorista/fordista de produção fabril em substituição à manufatura, descrito por Gramsci (1978).

Pretende-se evidenciar que, assim como a passagem da forma da produção citada implicou no condicionamento de um novo perfil de trabalhador, físico e ideologicamente definido, a passagem recente da forma taylorista/fordista para a pós-fordista e neoliberal tem forjado um novo perfil de trabalhador. Este processo vem produzindo e exigindo um complexo arca-

* Professor do Departamento de Sociologia e Ciência Política da Universidade Federal de Santa Catarina. seibel@chh.ufsc.br.

1 Agradeço a Benilson Borinelli pelos comentários críticos.

2 Limita-se a estes autores pela similaridade da base de suas pesquisas e das teses apresentadas.

\begin{tabular}{|l|l|l|l|l|l|}
\hline Civitas & Porto Alegre & v. 5 & n. 1 & jan.-jun. 2005 & p. 93-107 \\
\hline
\end{tabular}


bouço de arranjos ideológicos e institucionais de seletividade, exclusão e desqualificação dos antigos perfis dos trabalhadores e a afirmação de um novo. Em ambos os momentos, o processo de seleção de exclusão vem acompanhado de um movimento justificativo, de forte conteúdo moral, indicando características puritanas, porém diferenciados por certas condições históricas específicas.

\section{O declínio do welfare state}

O declínio do welfare state, nos padrões clássicos que assumiu basicamente entre o final da Segunda Guerra e o início dos anos 80, é uma questão relativamente amadurecida e consensual na literatura. Muitos são os argumentos que indicam este declínio e para melhor verificar esta questão destacam-se alguns desses argumentos.

Rosanvallón (1981), que concebe a Estado-providência como uma radicalização das funções do Estado-protetor, isto é, libertar a sociedade das necessidades e do risco, esclarece que a crise do welfare state (identificada como crise fiscal, crise de legitimação, crise de governabilidade) surgiu na conclusão do longo ciclo de desenvolvimento nacional e a associa com a crise do Estado-nação. Segundo o autor, o debate contemporâneo sobre o Estado-providência caiu no impasse da alternativa estatização/privatização. Ele considera estes dois cenários inaceitáveis, sendo que o cenário estatista exprime os limites de uma socialização e os impostos compulsórios; e o cenário privatista, a redução da redistribuição de renda e a ampliação da repressão social. A questão crucial apontada por Rosanvallón (1981) é se é possível produzir hoje uma nova equação econômico-social com os mesmos efeitos que a equação keynesiana de 40 anos atrás.

Também, para Vacca (1991), a crise do welfare state, que surgiu na conclusão do longo ciclo do desenvolvimento nacional, confunde-se, também, com a crise do Estado-nação. Este não é mais o terreno das lutas pela hegemonia. Destaca-se como pano de fundo deste processo o fim da economia nacional. Diante destas circunstâncias, aspectos essenciais do welfare state não seriam mais defensáveis, o que implica em repensar inteiramente a organização e o controle democrático da reprodução social e as combinações de público e privado, em outras palavras, as formas de regulação. 
Navarro (1991) analisa os argumentos das forças que, por toda a década de 80 , passaram a questionar a própria natureza do welfare state, fenômeno que, surgido após a Segunda Guerra Mundial, foi considerado por seus proponentes como uma vitória que historicamente não poderia ser revertida. $\mathrm{O}$ autor concentra-se basicamente na discussão sobre os gastos públicos do welfare state e não nas medidas de intervenção governamentais. O argumento mais forte das forças conservadoras é de que o welfare state é a causa principal da estagnação das economias ocidentais. Este argumento é justificado pelo fato de que a redistribuição de recursos produzida pelo welfare state teria acontecido em detrimento do setor privado e do público; do capital e do trabalho; da renda mais alta e da renda mais baixa; e dos setores produtivos da população (jovens) e dos improdutivos (velhos). Analisando os gastos de países capitalistas centrais (Grã-Bretanha, França, Alemanha Ocidental, Itália, Suécia e EUA), entre 1951 e 1980, Navarro (1991) observa que a maior parte dos cortes governamentais ocorreu justamente nos gastos sociais. Navarro (1991) buscou desconstruir a natureza ideológica dos argumentos antiwelfare e caracteriza o neoliberalismo como um keynesianismo militarista, considerando a relação entre a redução de gastos sociais, referindo-se ao governo Reagan, e o incremento de gastos militares.

Laurell (1998), refletindo numa perspectiva latino-americana, lembra que o limitado welfare latino-americano desenvolveu-se por meio de um pacto social entre Estado, empresas e sindicatos, no bojo do processo de substituição de importações, constituindo um sistema de proteção restrito e fortemente seletivo, carecendo de políticas de proteção de universalidade e equidade. A crise do welfare latino-americano foi produzida, por um lado, por um efeito combinado de ajuste fiscal, cortes salariais e desemprego e, por outro lado, por decadência/desmantelamento das instituições sociais. As novas concepções de políticas sociais definem necessidades sociais ancoradas na família e no mercado e remetem a proteção a uma condição de responsabilidade individual. Nesta mesma direção, Draibe (1992) considera a concepção das novas políticas sociais neoliberais como emergenciais e focalizadas.

Figueiredo (1997) investiga a substancialidade dos princípios de justiça para um julgamento defensável de uma política pública. Estes princípios são baseados em argumentos morais e políticos, levando em conta os princípios da justiça distributiva classificados como: direito se forem positivos e ideais; mérito se forem uma compensação ou contrapartida econômica das contribui- 
ções e do esforço dos grupos sociais; e necessidades se forem carências sociais definidas através de tipologias e de instrumentos metodológicos que permitam identificar grupos sociais focalizados. Estes princípios vem sendo debatidos e fixados como organizadores de novas políticas públicas, principalmente no que se refere aos novos bens públicos (órgãos de transplantes, por exemplo) ou novas categorias sociais de trabalhadores (denominados white collor). A questão mais implicante neste debate é o deslocamento potencial dos argumentos de definição normativa no acesso às políticas públicas do âmbito do direito para o âmbito da necessidade e do mérito.

Esping-Anderson (1995), comentando as perspectivas futuras do welfare state, apresenta um quadro de tendências assim classificado: modelo escandinavo, manutenção do pleno emprego por meio do emprego público; modelo neoliberal (Grã-Bretanha, EUA, Nova Zelândia, Austrália e Canadá), redução do protecionismo, flexibilização de trabalho e salário, centralização dos mecanismos de seletividade social; e modelo europeu-continental, centrado na família com a preservação da renda familiar.

Percebe-se que os condicionantes do declínio do welfare state nas últimas décadas são uma questão complexa e ainda não absolutamente clara. De qualquer forma os argumentos apontam para duas questões: o declínio de um modelo de proteção social e suas formas institucionais; e a redução da capacidade de oferta de emprego ao mesmo tempo que se aprimoram os processos de desregulação do trabalho e sua conseqüente desqualificação. Estes fatores combinados expressam um cenário social que apresenta inúmeros desafios. Entre estes desafios, a produção de uma miserabilidade estrutural que por sua vez tem encontrado como resposta política a criminalização. Este aspecto será tratado no item a seguir.

\section{A emergência do estado prisional: a criminalização do social}

\section{As teses de Ladipo}

Em seu estudo, Ladipo (2000) demonstra que o crescimento das prisões americanas nas décadas de 80 e 90 teve pequeno impacto na redução das 
taxas de criminalidade ${ }^{3}$ e na redução da prevalência do consumo de drogas. Salienta que, mesmo assim, os políticos americanos continuam a propor políticas que implicam no aumento da população prisional.

Até o final da década de 90, havia nos EUA dois milhões de detentos, três milhões de presos on probation, e 700 mil on parole (Ladipo, 2000). Segundo o autor, a principal causa do aumento no número de prisões americanas deve-se às mudanças nas políticas introduzidas pelos seus legisladores que se orientam por máximas como three strikes, truth in-sentencing e zero tolerance. Este crescimento chegou a $10 \%$ de todas as novas detenções nas prisões estatais em 1996. Mais da metade das pessoas foram encarceradas por crimes não-violentos contra a propriedade, abuso de drogas ou ofensas contra a ordem pública. $\mathrm{O}$ autor destaca que, apesar da ausência de qualquer correlação entre alterações na sua população prisional e nas mudanças no tipo de crime, os políticos americanos insistem na proposição de leis que aumentam os índices de criminalização, ${ }^{4}$ tendo razões para o fortalecimento desta atitude o apelo populista das leis de combate ao crime ${ }^{5}$ a pressão da imprensa americana pelo perfil das suas narrativas criminais e punitivas, utilizando recursos técnicos que provocam a espetacularização dos fatos criminais (reportagens por helicóptero; câmaras manuais de vídeo; julgamentos televisionados); e o desenvolvimento, na década de 90, de um "complexo industrial de prisões". A construção de prisões, fora dos grandes centros urbanos, produziu em pequenas cidades o incremento de emprego associado ao surgimento de uma indústria prisional através da privatização do sistema penitenciário.

Examinando as conseqüências do crescimento das taxas de criminalização sobre os direitos civis, ${ }^{6}$ Ladipo (2000) aponta que não somente os indiví-

3 “A população prisional dos E.U. A aumentou de meio milhão de pessoas em 1980 para mais de dois milhões de pessoas até o início do ano 2000" (Ladipo, 2000, p. 1).

4 Em 1995, a taxa de encarceramento por 100.000 habitantes era de 600, nos EUA (Ladipo, 2000).

5 Mesmo hoje, apesar de uma taxa oficial de desemprego abaixo da maior parte do que a dos países Europeus, o nível de insegurança no trabalho nos Estados Unidos é consideravelmente mais alto em relação à média européia. Sobretudo, se os sentimentos de punição são reflexo de um generalizado sentimento de insegurança eles também refletem a crescente desigualdade que tem marcado a sociedade americana (Ladipo, 2000, p. 10)

6 "Considerando que 6\% da população masculina americana na faixa etária dos 18 aos 64 anos está actualmente na prisão, em liberdade condicional, ou aguardando julgamento, as 
duos encarcerados sofrem restrições de liberdades civis, mas também aqueles que são submetidos a testes obrigatórios para investigar uso de álcool e drogas; identificação eletrônica e outras formas de restrições de liberdade de movimentos. ${ }^{7}$ Este processo implica na privação dos direitos civis dos condenados. 8

Da mesma forma, amplia-se o abismo entre a população negra e a branca nos EUA, sendo a explosão da população prisional negra americana desproporcional com relação à população branca. Entre 1984 e 1997, a proporção de homens brancos nas prisões subiu de $0.5 \%$ para $0.9 \%$. Durante o mesmo período, a percentagem de homens negros encarcerados subiu de 3,3\% para 7,2 \% (Ladipo, 2000). Ao final de 1997, havia 758.000 homens negros nas prisões, além de 274.000 on parole e ainda 902.000 on probation. Ao todo, mais de $18 \%$ de todos os homens adultos negros estavam sob alguma forma de supervisão correcional em 1997. O Bureau of Justice americano prevê que, se a taxa de encarceramento permanecer inalterada, $30 \%$ da população masculina negra será encarcerada "em algum período de suas vidas", segundo Ladipo (2000 p. 22).

instituições correcionais americanas têm dividido, desorganizado e desmoralizado a classe trabalhadora" (Ladipo, 2000, p. 21).

7 "Os números publicados pelo U. S. Bureau of Justice mostram que, até ao final de 1997, havia além 3,2 milhões de adultos em probation e ainda 685.000 em parole. Em outras palavras, "o total da população correcional chegava a 5,7 milhões de pessoas (aproximadamente 1 em cada 35 adultos) (Ladipo, 2000, p. 1).

8 Muitos desses indivíduos também perderam o direito de voto devido á condenações por crimes graves. De acordo com um recente relatório do Sentencing Project, 3,9 milhões de americanos, 1 em cada 50 adultos, tem hoje ou tiveram seu direito de voto perdido como resultado de suas condenações por crimes graves. E a perda tem sido maior entre os grupos que já são marginalizados dentro da sociedade americana. Considere, por exemplo, os afro americanos, porque dentre estes a taxa de aprisionamento é muitas vezes mais alta do que a média nos Estados Unidos, $13 \%$ da população negra americana teve negado o seu direito constitucional de participar no "processo democrático" americano. Até 1998, havia sete estados onde um em cada quatro negros havia sido permanentemente privado dos seus direitos civis. Ver o direito de voto, assegurado pelas campanhas de liberdade dos anos 50 e 60, ser desvalorizado hoje, em prol a expansão das prisões, nas décadas de 80 e 90, causa um profundo sentimento de desespero e amarga frustração (Ladipo, 2000, p. 17). 


\section{As teses de Wacquant}

Wacquant (2001), citando Lawrence Mead, ${ }^{9}$ analisa em seu livro o discurso conservador americano que incita o processo de criminalização e seus principais argumentos. Entre eles, aquele que aponta o fracasso do sistema de proteção social americano em absorver a pobreza devido a um "excesso de permissividade", questionando o caráter meritório dos programas sociais. Esta reação conservadora atinge também as razões sociológicas que apontavam a miséria como fator determinante de problemas sociais. A reação sugerida pelos conservadores indica, como solução, um Estado paternalista e punitivo e o retorno ao moralismo neovitoriano. Nesta concepção, o Estado paternalista deve ser também um Estado punitivo, que não deveria se preocupar com as causas da criminalidade das classes pobres, as quais devem ser punidas com eficácia e intransigência. A máxima "tolerância zero" deve ser o complemento policial indispensável ao encarceramento em massa.

Wacquant (2001) alerta que esta proposição de reafirmar a influência moral da sociedade sobre seus "maus" pobres e de "educar" o (sub) proletariado na disciplina do novo mercado de trabalho só é "florescente" porque encontra o interesse e a anuência das autoridades dos diversos países. Este novo ethos punitivo, necessário para justificar a escalada do Estado penal, converte-se no imperativo do "restabelecimento" da ordem (republicana) depois de terem se convertido aos benefícios do mercado e à necessidade de "menos Estado". Daí, deduz o autor, a renúncia para criar empregos e instalar comissariados junto aos novos complexos prisionais. Em síntese, engaiolar os inúteis e indesejáveis da ordem social nascente.

9 Lawrence Mead, autor de Beyond Entitlement: The Social Obligations of Citizenship, publicado em 1986, cuja tese de que Estado-providência americano dos anos 70-80 fracassou em reabsorver a pobreza, não porque seus programas de ajuda eram muito generosos, mas porque eram permissivos e não impunham obrigação escrita de comportamento a seus beneficiários. (In Wacquant, 2001, p. 43-44). Em outra obra (The New politics of Poverty: The Nonworking Poor in America), Mead argumenta que a questão social que domina as sociedade avançadas - tanto na América como na Europa (embora com atraso) - não é mais "a igualdade econômica", noção obsoleta, mas a "dependência dos pobres" incapazes de trabalhar por incompetência social e imperícia moral: "precisamos de uma nova linguagem política que faça da competência o objeto e não o postulado do debate. Precisamos saber como e porque os pobres são merecedores, ou não, e que tipos de pressão podem influenciar sobre seu comportamento." 
Para os partidários das políticas neoliberais de desmantelamento do Estado-providência, a "flexibilização" (redução dos gastos sociais, erradicação dos sindicatos, poda nas regras de contratação e de demissão, instauração de programas de trabalho forçado para os beneficiários da ajuda social) estimulou a produção de riquezas e a criação de empregos, ao mesmo tempo, observa que a hipertrofia do Estado penal sucede a redução do Estado social (Wacquant, 2001).

As prisões americanas estão repletas não de criminosos perigosos e violentos, mas de crimes vulgares condenados pelo direito comum, por envolvimento com drogas, furto, roubo, ou simples atentados à ordem pública, em geral oriundos das parcelas precarizadas da classe trabalhadora e, sobretudo, das famílias do sub-proletariado negro. Em 1998, a quantidade de condenados por contenciosos "não-violentos" reclusos nas casas de detenção e nos estabelecimentos penais dos Estados Unidos ultrapassou a cifra do milhão. Nas prisões dos condados, seis penitenciários em cada 10 são negros ou latinos; menos da metade tinha emprego em tempo integral no momento da prisão; dois terços provinham de famílias dispondo de uma renda inferior à metade do "limite de pobreza" (Wacquant, 2001, p. 80).

O incessante afluxo dos condenados quase quadruplicou em 16 anos alcançando os quatro milhões em 1997, ou seja, 3,26 milhões on probation e 685.000 on parole. Contam-se hoje 5,7 milhões de americanos nas "mãos da Justiça", número que representa quase 5\% dos homens com mais de 18 anos (Wacquant, 2001).

Proliferam-se os bancos de dados criminais assim como os meios e pontos de controle a distância, permitindo ampliar a capacidade de "captura" e de "observação" do aparelho penal. Atualmente, existem cerca de 55 milhões de "fichas criminais" (há uma década eram 35 milhões de fichas). Têm acesso a esses bancos de dados não apenas as administrações públicas, como também empregadores que, através da consulta, podem descartar os aspirantes a empregos com antecedentes. Nos estados de Illinois, Florida e Texas, esses arquivos foram disponibilizados em páginas da internet. Finalmente, uma vigilância intensiva e uma disciplina meticulosa, sobretudo por intermédio de revista semanal em busca de drogas, tornaram-se a principal atividade dos agentes de probation em muitas jurisdições (Wacquant, 2001). 
Estas condições traduzem o abandono do ideal da reabilitação, sendo este substituído por "nova penalogia", cujo objetivo não é mais prevenir o crime nem tratar os delinqüentes visando o seu eventual retorno à sociedade, mas isolar grupos considerados perigosos e neutralizar seus membros mais disruptivos mediante uma série padronizada de comportamentos.

Entre 1979 e 1990, os gastos penitenciários dos estados americanos cresceram $325 \%$ com seu funcionamento e $61 \%$ com sua construção, ou seja, três vezes mais rápido do que os créditos militares em âmbito federal (Wacquant, 2001).

Nascida em 1983, a indústria prisional conseguiu englobar aproximadamente $7 \%$ da população carcerária ( 0 , em 1983, 276.655, em 2001). Fortalecida com uma taxa de crescimento anual de $45 \%$, sua fatia de mercado tende a triplicar nos próximos cinco anos para aproximar-se dos 350.000 detentos (Wacquant, 2001).

A "guerra contra a droga" é considerada uma das causas mais importantes da explosão da população carcerária. As ações, neste contexto, explicam, com o abandono do ideal da reabilitação, a multiplicação dos dispositivos ultra-repressivos (generalização do regime das penas fixas e irredutíveis, elevação do limite de execução das sentenças pronunciadas, perpetuidade automática após o terceiro crime, punições mais rigorosas para os atentados à ordem pública) e, ao mesmo tempo, expressam o caráter fundamentalmente discriminatório das práticas policiais e judiciais implementadas no âmbito da política "lei e ordem" das duas últimas décadas (Wacquant, 2001, p. 95). ${ }^{10}$

A reclusão, que antes era um método que visava o controle das populações desviantes, principalmente de pobres e imigrantes europeus recémchegados em meados do séc. XIX, assume hoje um lugar central no sistema de controle do mercado de trabalho desqualificado, dos guetos urbanos e dos

10 A prova: os negros representam 13\% dos consumidores de droga (que corresponde ao seu peso demográfico) e, no entanto, um terço das pessoas detidas e três quartos das pessoas encarceradas por infração à legislação sobre drogas. Em 1995, seis novos condenados para cada 10 eram colocados atrás das grades [por portar ou comerciar drogas], e a esmagadora maioria dos presos por esses contenciosos provinha de bairros pobres afro-americanos, pela simples razão de que "é mais fácil proceder a prisões nos bairros operários estáveis ou os prósperos subúrbios de colarinhos brancos (Wacquant, 2001, p. 95) 
serviços sociais "reformados" com vistas a apoiar a disciplina do trabalho assalariado dessocializado (Wacquant, 2001).

O sistema penal contribui diretamente para regular os segmentos inferiores do mercado de trabalho, num primeiro momento, comprimindo artificialmente o nível de desemprego ao subtrair, à força, milhões de homens da "população que busca um emprego"; num segundo momento, produzindo um aumento do emprego no setor de bens e serviços carcerários (Wacquant, 2001, p. 97).

O sistema carcerário substitui o gueto como instrumento de encerramento de uma população considerada tanto desviante e perigosa como supérflua no plano econômico. Desde a crise do gueto, simbolizada pela grande "onda" de rebeliões urbanas na década de 60 , a prisão faz o papel de "gueto" ao excluir as frações do subproletariado negro, persistentemente marginalizado pela transição para a economia dual dos serviços e pela política de retirada social e urbana do estado federal (Wacquant, 2001, p. 98).

Os sistemas burocráticos, jurídico e social articulados organizam uma rede de regulamentação punitiva que, por intermédio de dispositivos panópticos, sofisticados e intrusivos, colocam as populações pobres sob uma supervisão meticulosa, e pelo estreitamento da vigilância informatizada que utiliza arquivos sociais e arquivos policiais, para melhor aplicar as decisões de suspensão dos subsídios familiares em caso de delinqüência reincidente de um adolescente ou para encontrar testemunha ou suspeito retratando as ramificações das ajudas sociais (Wacquant, 2001, p. 125). ${ }^{11}$

11 “[...] ...Holanda, líder europeu inconteste em matéria de panptismo administrativo. [...] tendo desenvolvido, alem do recurso ao sistema penitenciário (cuja capacidade de ocupação triplicou entre 1985 e 1995), múltiplos dispositivos que colocam sob supervisão permanente os beneficiários de ajudas sociais, os estrangeiros e os jovens considerados "de riso". Assim, os arquivos dos serviços sociais holandeses estão diretamente conectados aos da administração fiscal, de modo a serem capazes de detectar e penalizar os "assistidos", que, teriam um emprego. Uma serie de medidas legislativas [...] levou as administrações do Estado a colocarem seus bancos de dados em rede a fim de barrar o acesso de imigrantes irregulares ao mercado de trabalho assim como ao conjunto dos serviços públicos, educação, alojamento, cobertura social, saúde. Tendo por efeito perverso mergulhar essas populações na clandestinidade mais adiante, oblitera os direitos elementares (à assistência jurídica, à escolarização dos filhos, à assistência medica de urgência, entre outros) que as leis são reconhecidas pelas convenções internacionais, nas quais a Holanda figura entre os primeiros signatários, e estimular um vasto comércio de documentos falsos" (Wacquant, 2001, p. 125). 
Wacquant (2001) alerta que se propaga pela Europa um novo senso comum penal neoliberal, que amplia a repressão aos delitos menores, através do agravamento das penas, da não-reabilitação delinqüente juvenil, da vigilância permanente sobre as populações e os territórios considerados "de risco", a desregulamentação da administração penitenciária e a redefinição da divisão do trabalho entre público e privado. Este senso comum se desenvolveu em perfeita harmonia com o senso comum neoliberal em matéria econômica e social e desdenha qualquer consideração de ordem pública e cívica para estender à racionalidade economicista, o imperativo da responsabilidade individual e o dogma da eficiência do mercado ao domínio do crime e do castigo. Isto pode ser percebido na política do New Labour, do primeiro-ministro trabalhista John Major que assumiu como sua a política de "penalização da miséria", como um complemento funcional indispensável à imposição do trabalho assalariado precário e sub-remunerado e da redução draconiana da cobertura social. Desregulamentação econômica e sobre-regulamentação penal desdobram-se concomitantemente: o desinvestimento social acarreta e necessita do superinvestimento carcerário, único meio capaz de suprimir os deslocamentos decorrentes do desmantelamento do Estado-providência e a generalização da insegurança social.

\section{A experiência histórica das transições}

Com os estudos de Ladipo (2000) e Wacquant (2001) pôde-se perceber uma dinâmica de transição social que já se observou em outras condições históricas, neste caso a transição de uma matriz de produção fordista para um modelo neo-fordista. Esta dinâmica transitória produz conseqüências estruturais profundas, principalmente sobre os trabalhadores, uma vez que explicita e acelera um processo de exclusão e inclusão seletiva, em que os personagens não mais serão os mesmos, nem individualmente nem na condição de classe ou grupo social.

Em Americanismo e Fordismo, de Gramsci (1978), encontra reflexões elucidativas desta dinâmica transitória e suas conseqüências:

[...] quem poderia enumerar o "custo", em vidas humanas e em dolorosas sujeições dos instintos, da passagem do nomadismo à vida sedentária e agrícola! Ligam-se a ela as primeiras formas de servidão a gleba e dos ofícios, etc. [...] Até agora todas as mudanças do modo de ser e viver se verificaram através da coer- 
ção brutal, através do domínio de um grupo social sobre todas as forças produtivas da sociedade; a seleção ou "educação" do homem apto para os novos tipos de civilização, para as novas formas de produção e de trabalho, foi realizada com o emprego de brutalidades inauditas, lançando no inferno das subclasses os débeis e os refratários, ou eliminando-os simplesmente. [...] as crises de libertinismo foram numerosas cada época histórica teve a sua (Gramsci, 1978 p. 393).

Gramsci (1978, p. 393) salienta que a violência da exclusão, ao mesmo tempo em que elimina os débeis e refratários, é justificada por ideologia puritana:

[...] Quando a pressão coercitiva é exercida sobre todo o complexo social (o que sucede especialmente depois da queda da escravidão e do advento do cristianismo), desenvolvem-se ideologias puritanas que moldam a forma exterior da persuasão e do consentimento ao uso intrínseco da força. [...] os instintos que hoje devem ser superados como ainda bastante "animalescos", construiriam, na realidade, um progresso notável em relação aos anteriores, ainda mais primitivos.

Gramsci (1978, p. 396), ao se referir à emergência do paradigma fordista/taylorista e às condições sociais e culturais, afirma:

Os novos métodos (taylorismo e racionalização em geral) exigem uma rígida disciplina dos instintos sexuais (do sistema nervoso), um reforçamento da "família" em sentido amplo, a regulamentação e a estabilidade das relações sexuais [...] pois os novos métodos de trabalho estão indissoluvelmente ligados a um determinado modo de viver, de pensar e de sentir a vida; não é possível obter êxito num campo sem obter resultados tangíveis no outro. Na América, a racionalização do trabalho e o proibicionismo estão indubitavelmente ligados: os inquéritos dos industriais sobre a vida íntima dos operários, os serviços de inspeção criados por algumas empresas para controlar a "moralidade" dos operários são necessidades do novo método de trabalho.

Então, analisando a experiência pioneira da Ford, em associar altos salários e níveis inéditos de produtividade, Gramsci (1978, p. 406) esclarece que:

[...] A Ford exige uma discriminação, uma qualificação, para os seus operários que as outras indústrias ainda não exigem; um tipo de qualificação diferente, nova, uma forma de consumo de força de trabalho e uma quantidade de força consumida no mesmo tempo médio mais onerosas e extenuantes do que em outras empresas, força que o salário não consegue reconstituir em todos os casos, nas condições determinadas pela sociedade. 
Assim, Gramsci (1978, p. 406) prevê as conseqüências desta nova racionalidade sobre o conjunto dos trabalhadores:

[...] verificar-se-á, inevitavelmente, uma seleção forçada, uma parte da velha classe trabalhadora será impiedosamente eliminada do mundo do trabalho e talvez do mundo tout court. [...] levaria à degeneração física e à deterioração da raça, destruindo todas as forças de trabalho.

O advento do novo sistema produtivo implica, portanto, na desqualificação do perfil tradicional, tornando-o arcaico com a introdução de um novo. Destaca-se aqui a desqualificação de um perfil de trabalhador constituído no âmbito da forma manufatureira de produção, cujas habilidades compreendiam ainda um grau de concepção daquilo que deveria ser produzido além da utilização da força física, associada seu trabalho, um sistema de subcontratação no qual, não raro, incluía membros da própria família.

O declínio do modelo fordista/taylorista e a emergência de novas formas de trabalhos e suas características estão entremeados por um processo de transição:

De um perfil de trabalhador que associa destreza física com padrões de conhecimento técnico para um perfil de trabalhador cujas necessidades de qualificação não têm mais caráter fabril (manuseio de equipamentos complexos);

Do declínio do conceito de profissão (permanente, vitalícia) - no extremo a idéia de Beruf assinalada por Weber (1864-1920) para a identidade com uma ocupação (sazonal, temporária, fragmentada), dispensa o perfil tradicional de trabalhador fabril, passando a incorporar um contingente cada vez maior de trabalhador com qualificações intelectuais (white collor) e a dispor de forma não regular de um trabalhador com baixas qualificações cognitivas e vínculos institucionais e sociais precários.

Da fixação geo-espacial junto à fabrica ou ao bairro operário e, conseqüentemente, da residência fixa e da moradia própria, de vínculos com a comunidade, para a perspectiva de residir temporariamente, de lugar de residência associado ao lugar do emprego, de migração como possibilidade constante e banal;

O vínculo com a empresa, de perspectiva perene ou prolongada, para um vínculo pueril, sem estabilidade;

A garantia de acesso à proteção social através da condição de direito na forma de programas de assistência para a busca de (alguma) proteção no mercado ou sub- 
missão aos serviços públicos precários e à assistência social filantrópica; e um processo de declínio de relações morais.

Do conjunto destas características, surgem reflexões sobre as dicotomias referentes às políticas de bem-estar social derivadas de um Estado prisional ou de uma reavaliação nas concepções de justiça que orientam a proteção social.

\section{Considerações finais}

Neste trabalho, pretendeu-se evidenciar alguns elementos empíricos e conceituais para o esclarecimento do fenômeno contemporâneo da violência e da reação das forças políticas e institucionais deste fenômeno. Após as reflexões aqui sistematizadas, propõe-se as seguintes hipóteses:

O fenômeno da violência em escala mundial acontece pari passu a um conjunto de transformações nas formas do sistema produtivo capitalista que combina transformações na matriz produtiva, no caráter do trabalho e no modelo de proteção social;

A ausência de perspectivas de inclusão social e de trabalho profissional, associada à precarização do sistema público de proteção social, reforça o caldo cultural das práticas de incivilidades públicas, ante-sala do mundo da violência;

A lógica de dispensabilidade de contingentes populacionais como força de trabalho, associada à ausência de políticas massivas de requalificação técnica, é análoga à lógica do rompimento do compromisso com a recuperação social do penado ou do drogado;

Ao trabalhador pobre, resta qualificação moral como atributo que lhe permita acesso ao trabalho. $\mathrm{O}$ requisito da qualificação moral consiste em apresentar um histórico pessoal livre de implicações jurídicas ou penais. Em outras palavras, "ficha limpa" ou "atestado de idoneidade"; e

A resposta política conservadora à condução desta passagem histórica é a emergência de um Estado prisional como sugerem Ladipo (2000) e Wacquant (2001). Com este Estado, afirma-se uma percepção da miséria como fenômeno criminalizante e reage-se à miséria com a lógica punitiva do "pão e palmatória", isto é, um sistema que, ao mesmo tempo que oferece proteção social, controla e pune. 


\section{Referências}

DRAIBE, Sônia. As políticas sociais e o neoliberalismo. Reflexões suscitadas pelas experiências latino-americanas. Revista da USP. Dossiê Liberalismo/neoliberalismo. n. 17, p. 86-101, mar.-abr.-maio 1993.

ESPING-ANDERSEN, Gosta. O futuro do Welfare state na nova ordem mundial. Lua Nova, n. 35, 1995.

FIGUEIREDO, Argelina Cheibub. Princípios de Justiça e a Avaliação de Políticas Públicas. Lua Nova, n. 39, p. 73-104, 1997.

GRAMSCI, Antônio. Americanismo e Fordismo. Maquiavel, a Política e o Estado Moderno. 3. ed. Tradução de Luiz Mário Gazzaneo. Rio de Janeiro: Civilização Brasileira, 1978.

LADIPO, David. O retrocesso da liberdade. Contabilizando o custo da tradição prisional americana. Cadernos de Ciências Sociais, n. 25. Programa de Pós-Graduação em Sociologia Política/UFSC, Florianópolis, 2000.

LAURELL, Asa Cristina. Para um novo estado de bem-estar na América Latina. Lua Nova, n. 45, p.187-204, 1998.

MEAD, Lawrence. Beyond entitlement: the social obligations of citizenship. New York: Free Press, 1986.

- The new politics of poverty: the nonworking poor in America. New York: Basic Books, 1992.

NAVARRO, Vicente. Welfare e keynesianismo militarista na Era Reagan. Lua Nova, n. 24, p. 189-210, 1991.

ROSANVALLON, Pierre. A crise do Estado Providencia. Lisboa: Inquéritom, 1984.

VACCA, Giuseppe. Estado e mercado, público e privado. Lua Nova, n. 24, p. 150$164,1991$.

WACQUANT, Löic. As prisões da miséria. Rio de Janeiro: Jorge Zahar, 2001.

Texto recebido em dezembro de 2004 e aprovado em janeiro de 2005. 